\title{
AS DIVERSAS APROXIMAÇōES À TERAPÊUTICA DE GRUPO
}

\author{
DAVID ZimMERMANN *
}

A psicoterapia de grupo, em seu meio século de existência, desenvolveu-se muito, notadamente depois da II Guerra Mundial, quardo grande número de psiquiatras e psicanalistas se interessou por esta nova modalidade de tratamento, em razão da desproporção existente entre a quantidade de pacientes necessitados de assistência e o número relativamente pequeno de psicoterapeutas para atendê-los. Este desenvolvimento pode ser apreciado quer pela extensão do emprêgo do método, quer pelo número de publicaçōes a que deu lugar. Assim, nos Estados Unidos, mais da metade dos hospitais psiquiátricos emprega uma das múltiplas formas de psicoterapia de grupo; quanto ao número de publicações, verifica-se que, se no período de 1900 a 1919 surgiram apenas 11 contribuições, de 1920 a 1929 apareceram 20 trabalhos; a seguir, de 1930 a 1939 contam-se 90 publicações e, já no período que vai de 1940 a 1949 , mais de 600; até fevereiro de 1954 registravam-se mais de 1.400 títulos bibliográficos na psicoterapia de grupo. Atualmente, só nos Estados Unidos, a média anual de publicações é de 125 títulos ${ }^{11}$. Nesse pais existem duas organizações - American Society of Group Psychotherapy and Psychodrama e American Psychotherapy Association Inc., com tendência internacional no que diz respeito à filiação de sociedades congêneres - dedicadas ambas à Iormação de terapeutas, bem como à publicação de revistas especializadas (Group Psychotherapy e International Journal of Group Psychotherapy editadas, respectivamente, pela Beacon House Inc., New York e International Universities Press, Inc., New York). Além disso não há, pràticamente, revista de psiquiatria ou de psicoterapia que não contenha, vez que outra, contribuiçōes à psicoterapia de grupo. Até mesmo as revistas psicanaliticas - como o International Journal of Psychoanalysis, o Psychoanalytic Quarterly, a Revue Française de Psychanalyse e a Revista de Psicoanalisis - tão restritas na seleção de seus artigos, têm publicado trabalhos relativos à psicoterapia de grupo. Outro dado que comprova o crescente desenvolvimento da psicoterapia de grupo é o fato de a maioria

Este trabalho é uma modificação do relatório do tema oficial “Hechos y Teorias en Psicoterapia de Grupo" do I Congresso Latino-Americano de Psicoterapia de Grupo, realizado na Faculdade de Ciencias Médicas da Universidade de Buenos Aires em setembro de 1957 e fêz parte de uma tese inaugural apresentada à Faculdade de Mcdicina de Pôrto Alegre em agôsto do mesmo ano.

* Psiquiatria do Hospital São Pedro e Assistente de Ensino da Cadeira de Clínica Psiquiátrica da Faculdade de Medicina de Pôrto Alegre. 
dos manuais e tratados de psiquiatria recentes não deixaram de mencioná-la. Assim, o Modern Clinical Psychiatry de A. Noyes, em sua $4^{a}$ edição de $1953{ }^{25}$, dedica a têrça parte do capítulo destinado à psicoterapia à explanação da psicoterapia de grupo, sendo de notar que na edição anterior, de 1948, não fôra feita qualquer referência a êste método de tratamento.

Devido a êste pujante desenvolvimento torna-se oportuna uma revisão biblicgráfica das principais contribuições ao tema. Esta revisão será feita tendo em mente proporcionar uma visão panorâmica das várias formas de enfoque psicoterapêtico de grupo, ou seja, mais amplamente, a multiplicidade de métodos e orientações empregados.

Tal como ocorre na psicoterapia individual, existem, atualmente, várias formas de psicoterapia de grupo e, agravando a questão do estudo das mesmas, há a considerar o problema de que a situação terapêtica de grupo é muito mais complexa. Esta complexidade deriva, em primeiro lugar, do fato de se proceder ao tratamento de muitos pacientes ao mesmo tempo e, em segundo lugar, da circunstância de serem numerosas as combinações psicoterapêuticas propostas pelos autores. Em conseqüência, para uma revisão em conjunto, impōe-se uma classificação das formas de psicoterapia. A meu ver, o melhor critério de classificação é aquêle que leva em conta um maior ou menor emprêgo de processos repressivos, ou inversamente, da técnica da terapêutica analítica. Seguindo êste critério, distinguem-se quatro formas principais de psicoterapia de grupo: a repressiva, a didática, a psicodramática e a psicanalítica ${ }^{38}$.

\section{MÉTODO REPRESSIVO}

Pratt ${ }^{29}$, o fundador da Psicoterapia de Grupo e o primeiro a empregar êste método em 1905, partiu da observação do convivio de pacientes tuberculosos enquanto aguardavam em uma sala de espera de um dispensário, verificando que entre os mesmos se estabeleciam relações emocionais que tornavam os pacientes mais animados. Isto o inspirou a reuní-los em aulas semanais, para administrar-lhes um curso de higiene pessoal. Nestas aulas, discutia as atitudes dos doentes em face da infecção tuberculosa em relação aos familiares e amigos; comparava as diversas maneiras dos pacientes se defrontarem com a doença; dava conselhos e esperanças de cura. Considerou as reuniōes como proveitosas porque, invariàvelmente, os pacientes melhoravam, tornando-se otimistas e mais corajosos. Ulteriormente empregou essas aulas com outros pacientes crônicos: cardíacos, diabéticos e psiconeuróticos. Os resultados favoráveis foram atribuídos, de acôrdo com as idéias de Deferine, à confiança que o grupo depositava no terapeuta.

Pratt faz reuniões semanais, de hora e meia, com mais ou menos vinte pacientes. Quatro ou cinco sentam ao lado do terapeuta: são os casos mais antigos e com mais proveito. Os demais sentam em sua frente. Ảs vêzes comparecem às reuniōes, sentando-se no lugar de proeminência, antigos pacientes curados, como exemplo aos novos sôbre os resultados do tratamento. 
Começa as sessōes fazendo a chamada dos pacientes, referindo para cada um o número de sessões já assistidas. A seguir, uma secretária distribui papéis onde os pacientes, sem assinar seu nome, devem anotar suas melhoras ou persistência de sintomas. Segue-se um exercicio de relaxamento muscular e mental, depois do que é feito um pequeno discurso, versando sôbre problemas emocionais simples, ou então leitura de trechos de prosa ou verso de conteúdo edificante.

A denominação atual do método, antes chamado "Reeducação Moral, Persuasão", é de "Aulas de Contrôle do Pensamento" (Thought Control Class). Esta denominação deve-se a uma paciente de pouca instrução que obteve uma "cura milagrosa". Pratt, em alguns casos, dado o brilho e a rapidez das curas, tem dificuldade em explicá-las. Considera, entretanto, elucidativo, nesse sentido, o trabalho de Herbert I. Harris ${ }^{16}$, que julga como cperantes, no método de Pratt, os seguintes fatôres: a) desejo de aprovação do líder, o terapeuta, e conseqüentemente, a promoção de rivalidades no grupo no sentido de melhoras ou cura; b) aumento do sentimento de importância nas promoções, tendo assento nos lugares de mais evidência (considerados lugares de honra); c) o apêlo à correção de aspectos imaturos da vida $€$ mocional do paciente; d) o testemunho de pessoas que aproveitaram o tratamento e seu entusiasmo pelo lider; e) o fator sugestivo desemFcnhado no grupo pelo relaxamento muscular e mental. Aderindo à mesma linha do fundador da Psicoterapia de Grupo, mas sem acrescentarem algo de novo, podem-se citar os trabalhos de Buck ${ }^{7}$, Rhoades ${ }^{30}$ e Snowden ${ }^{35}$.

Usando tésnicas repressivas com maior intensidacie que Pratt, Chapel, Stephano, Rogerson e Pike " trataram pacientes com úlceras gástricas. A base do tratamento, em resumo, consistiu no seguinte: a) contrôle das preocupações e "tormentos", substituindo-os por pensamentos felizes; b) proibição de discutir seus sintomas com os familiares e amigos; c) diminuição da disciplina em relação aos regimes alimentares; d) auto-sugestão; e) sugestão induzida, no sentido de assegurar boa digestão, mediante bons pensamentos e sono tranquiilo.

Abraham A. Low 21 é, dentre os que empregam a repressão, quem a usa com maior intensidade, de forma ostensiva e quiçá violenta. Em 1937, Low fundou. com 30 psicóticos que receberam alta após tratamento de "choque", uma entidade que se denominou "Recovery Inc.". A base do processo terapêutico empregado consiste em substituir a linguagem usada pelo paciente, capaz de engendrar tensōes emocionais e perpetuar os sintomas, por expressões afirmativas, propiciadas pelo médico, dirigidas no sentido da saúde mental.

A terminologia da "Recovery Inc." consta, pràticamente, de duas expressões: "sabctagem" e "autoridade". Quando, por exemplo, o paciente diz que seu sintoma é "inccntrclável" ou "insuperável" está fazendo um diagnóstico e prognóstico, que constituem uma "sabotagem ao diagnóstico e prognóstico do médico", pondo em dúvida sua autoridade. Uma vez que êste afirmou um diagnj́stico, não se permite mais aos pacientes fazerem auto-diagnósticos (selfdiagnosing). Após dois meses na "Recovery Inc.", o paciente deve ter abandonado ou diminuido seus sintomas: na hipótese contrária é considerado "sabotador". Isto significa que ainda não aprendeu a deixar de resistir ao médico, devendo envidar maiores esforços nesse sentido. 


\section{MĖTODO DIDÁTICO}

O método didático usa. como meio terapêutico, conferências, leituras e discussão de livros e artigos de revistas, bem como o relato de casos clínicos, reais ou imaginários.

O método didático foi empregado pela primeira vez em psicóticos por Lazell 19, em 1921. Reuniu êsse autor diversos esquizofrênicos, para os quais ministrou uma série de palestras sôbre desenvolvimento da libido, masturbação, homossexualidade, sentimento de inferioridade, etc. Os resultados foram considerados satisfatórios, uma vez que pacientes aparentemente inacessíveis passaram a fazer perguntas sôbre os temas tratados. Segundo Lazell 19b, as vantagens do método são as seguintes: uma transferência positiva é facilitada, pelo aspecto impessoal das comunicações, através das conferências, havendo melhor aceitaçåo do material do que numa psicoterapia individual.

Marsch ${ }^{22}$ considera os pacientes mais como estudantes, e o método um procedimento mais educacional do que médico. Após a matricula, é solicitada a máxima cooperaçāo dos estudantes, tanto na assistência regular ao curso como na participação nos temas tratados, fazendo perguntas e dando respostas, ao terapeuta e aos colegas. Os temas consistem em escrever, por exemplo, "Minhas lembranças mais primitivas", "Os componentes do meu complexo de inferioridade", "As coisas de que tenho mêdo", etc. As conferências versam sôbre a situação familiar, os fundamentos da personalidade da criança, vida emocional, vida social, vida sexual, etc.

Os mecanismos terapêuticos, segundo Wender ${ }^{41}$, são devidos a quatro fatôres: a intelectualização, a transferência, a catarse e a interação no grupo.

Blackmann ${ }^{6}$ iniciou seus trabalhos fundando, em uma sala hospitalar, um clube literário com um jornal para esquizofrênicos crônicos. O número de pacientes foi de 25 , que elegeram para presidente um catatônico em mutismo, o qual em seguida voltou a falar.

O autor que mais contribuiu na divulgação e sistematização do método didático foi Klapman ${ }^{19}$.

\section{MÉTODO PSICODRAMATICO}

Êste método foi criado e desenvolvido pelo vienense Jacob L. Moreno, a partir de 1911. Afirma Moreno que tôdas as psicoterapias são psicodramáticas, mas que a sua o é em maior extensão. A base teórica do método, segundo Klapman ${ }^{18}$, é a seguinte: o Ego da criança só se desenvolve com a ajuda dos Egos auxiliares que são a mäe, o pai, os professôres, etc.; atinge, assim, normalmente a maturidade, tornando-se, por sua vez, um Egoauxiliar. O neurótico e o psicótico não atingiram ao estágio de desenvolvimento completo, necessitando, em conseqüência, de Egos-auxiliares, os quais são propiciados pela técnica psicodramática. 
Segundo a concepção de Moreno, o meio terapêutico deve ser separado do agente terapêutico, que é o terapeuta. O meio terapêutico pode ser uma simples luz, fixa ou em movimento, um som repetido, ou algo mais complicado, como, por exemplo, uma boneca, uma música, um filme, uma dança e, finalmente, o complexo de meios e agentes terapêuticos que constituem o psicodrama. Seguindo esta concepção de empregar um dêsses meios terapêuticos, existem vários trabalhos; citarei alguns, mais a título de curiosidade: com titeres, de R. Cohen ${ }^{10}$; com música, de Altshuler ${ }^{2}$, McKay ${ }^{23}$ e Ward ${ }^{39}$; com dança, de Chace ${ }^{8}$; com filmes cinematográficos, de Rome ${ }^{31}$ e Prados ${ }^{27}$.

Segundo Müller ${ }^{24}$, o método psicodramático utiliza cinco instrumentos principais: a cena, o paciente, o diretor, os Egos-auxiliares e o público.

1) A cena: o espaço cênico é um prolongamento da vida e da experiência da vida real. A realidade e a fantasia ali não entram em conflitos: as ilusões e alucinaçõões ficam no mesmo nivel da percepção sensorial normal. A cena permite ao paciente se libertar de tensões intoleráveis, encontrando o equilibrio comprometido.

2) O paciente: será, no palco, como é na realidade; desempenhará seu papel de acôrdo com a inspiração do momento. Dols fatóres são de importância capital: a espontaneidade e a dramatização. O paciente inventa um papel qualquer, reproduz um cena passada ou um problema atual, ou ainda futuro.

3) o diretor: transforma tudo o que o paciente lhe oferece em ação dramática. O diretor, na qualidade de terapeutc, está autorizado a chocar o paciente, fazê-lo rir ou chorar. Na qualidade de analista, o diretor completará suas interpretações pessoais graças às informações prestadas pelos espectadores (marido, mulher, amigos e vizinhos).

4) Os Egos-auxiliares: são extensões do diretor, na qualidade de investigadores e terapeutas: ao mesmo tempo, são partes do paciente pur representarem personagens reais ou imaginárias do seu drama vital.

5) O público: o que interessa é a ressonância da opınião da assistência. As reaçōes desta devem ser espontâneas, pois só assim pode o paciente encarar (introjetar?) o público na manifestação da sindrome coletiva dramatizada no páco.

Em sua técnica utiliza Moreno uma platéia e um palco, êste provido de um jôgo de luzes usadas convenientemente, de acôrdo com as situaçōes emocionais em foco. A platéia consta de três planos ou circulos concêntricos. No primeiro plano, próximo ao palco, sentam os pacientes que mais participam no psicodrama, o diretor e seus auxiliares (enfermeiros, psicólogos e assistentes sociais), isto é, os Egos-auxiliares especialmente treinados para tal fim. No plano mais afastado, sentam os pacientes recém-admitidos no tratamento. Ficam no plano intermediário os pacientes com grau variado de estágio terapêutico, bem como os parentes e amigos do paciente, os quais, dependendo do caso e das circunstāncias, podem participar ativamente no psicodrama. Uma estenógrafa anota os diálogos e as cenas para estudo ulterior.

As cenas representadas podem ser escritas peios pacientes ou pelo médico, versando sôbre temas gerais ou especiais de um paciente. Neste caso, as cenas derivam da história clínica, via de regra prèviamente investigada. Pode ainda a cena surgir espontânea ou improvisadamente no palco e a propósito de um tema correlato ou não. $A$ espontaneidade é um dos elementos fundamentais no método de Mureno e o diretor exorta o paciente a crida instante a ser o mais espontâneo possínel. A medida que o paciente descreve suas dificuldades com as pessoas de seu ambiente, atual ou passado, ou então suas alucinaçoes e delírios, o diretor vai introduzindo no palco os Egos-auxiliares (ajudantes treinados ou outros pacientes) que funcionam de acôrdo com a descriç̃o feita pelo paciente. Assim, por exemplo, se o doente menciona uma 
cena ccm o cônjuge ou pai, ou a voz de um espirito, seus representantes são introduzidos no palco, reproduzindo inúmeras vêzes $e$ de várias formas, até satisfazer o doente, a suposta situaçăo, incriminada pelo estado atual.

Inúmeros autores, sobretudo nos Estados Unidos, empregam atualmente o método psicodramático. Herriot ${ }^{33}$, for exemplo, descreve bons resultados no tratamento de pacientes com alta hospitalar, mas que têm dificuldade em retornar ao ambiente familiar. Tais dificuldades, e de acôrdo com o relato do paciente, são representadas, dramatizadas aos poucos, conforme sua capacidade crescente. O importante é que desde a primeira tentativa o paciente não deve fracassar. Sòmente as situaçōes capazes de serem levadas a efeito com sucesso é que devem ser ensaiadas.

Procedimento semelhante tem Ernest Fantel, em casos de neuroses traumáticas de guerra ${ }^{14}$.

\section{MÉTODO PSICANALITICO}

Com pєquenas variacões, observa-se uma série de fatos comuns nos grupos terapêuticos conduzidos com orientação psicanalitica, motivo pelo qual serão expostos em conjunto. Assim, quanto ao número de pacientes, êste é sempre menor do que nos métodos precedentes. Constituem os denominados "pequenos grupos", desde dois a três pacientes até o máximo de dez, com uma média de 7 pacientes para cada grupo. A freqüência média das sessōes é de uma ou duas por semana, sendo excepcionais três e quatro sessões semanais. A duração das sessões, variando em média desde 45 minutos até 1 hora e 15 minutos, está, em regra, na razão inversa da sua freqüência. Alguns autores preferem a seleção prèvia dos pacientes, feita tanto por métodos individuais como pelos de grupo, ao passo que outros não fazem seleção. O critério de agrupamento dos pacientes pode ser orientado pelo diagnóstico clínico, pelos sintomas, pelas sindromes ou problemas, pelo sexo, pela profissão, pela raça, etc. $O$ critério mais aceito, por ser mais funcional, é o do agrupamento por contraste. Psicoterapeutas há que trabalham com grupos fechados, mas a maioria prefere grupos abertos, isto é, grupos nos quais sempre pode entrar mais um paciente desde que ocorra vaga ou haja conveniência. A introdução de um novo paciente no grupo constitui às vêzes problema sério, tanto para o novato, como para o grupo já em funcionamento. A maioria dos autores limita-se a atender os pacientes exclusivamente no grupo, ao passo que outros associam psicoterapia individual. Alguns psicoterapeutas trabalham com um ou dois observadores.

Muito resumidamente, são estas as características gerais dos grupos terapêuticos em que é empregado, com adaptações, o método psicanalítico.

Entretanto, dentro da psicoterapia analítica de grupo cabe assinalar duas orientaçōes distintas: (1) a que focaliza o individuo e dirige as interpretações para êste ou para as relações que se estabelecem entre um ou dois pacientes do grupo; (2) a que focaliza o grupo como um todo e para 
êste todo encaminha primordialmente as interpretaçōes. Estas duas formas de aproximação corresponđem à evolução natural da psicoterapia analitica de grupo. Com efeito, nas primeiras contribuições nota-se o transplante direto, sem modificações, dos conhecimentos e técnicas da análise individual para a de grupo. Em conseqüência, nessa primeira orientação, o terapeuta dirige suas intervenções e interpretações não ao grupo mas aos pacientes do grupo; ao passo que na orientação seguinte as interpretações são dirigidas ao grupo como um todo, como uma estrutura dinâmica própria e, como tal, diferente da soma dos seus componentes. Essas duas orientações correspondem, respectivamente, ao que se denomina de "análise em grupo" e "análise através do grupo". Desde já cumpre esclarecer que, em realidade, quando se trata de psicoterapia analítica de grupo, não cabe esta diferenciação, visto que os fenômenos inconscientes de grupo simplesmente existem e como tais têm de ser levados em conta. A não se proceder assim, cometer-se-á êrro semelhante ao de uma psicoterapia individual que deixasse de considerar e interpretar o fenômeno transferencial.

Antes de descrever estas duas orientações, torna-se necessário uma advertência. Os autores que se dirigem aos componentes do grupo individualmente nem por isso deixam de salientar, e às vêzes com muita ênfase, a importância do grupo como fato: e meio terapêtico. Apesar disto, não focalizam o grupo como uma totalidade, como uma estrutura dinâmica, ou unidade funcional, e muito menos analisam essa estrutura. Quando fazem referencia ao grupo í mais no plano de organização ccnsciente.

\section{a) Orientação psicanalítica que visa o indivíduo no grupo}

Històricamente, Simmel pode ser considerado como o primeiro psicanalista a c:npregar os conhecimentos analíticos na terapia de grupo, pois na I Grande Guerra tratou êle as neuroses de guerra mediante a "ab-reação ativa" em grupo; entretanto, deve-se considerar Schilder como o verdadeiro introdutor do método analítico na psicoterapia de grupo. No procedimento de Schilder ${ }^{3}$, os pacientes são preparados antes de ingressarem no grupo, ensinando-se-lhes a associação livre, ao mesmo tempo $\mathrm{cm}$ que se colhe a história individual. Durante o tratamento fazem-se também sessões individuais. As atitudes dos pacientes em relação ao terapcuta, ou a outros componentes do grupo. freqüentemente expressam amor ou ódio, os quais podem tei ccmo resposta dos outros a simpatia ou antipatia.

Ncs trabalhos de Schilder encontramos observações de muito interêsse, mas que não foram devidamente elaboradas. Assim, afirma Schilder que a ligação médicopaciente é relativamente mais intensa do que a que estabelecem os pacientes entre si. Como exemplificação, diz que o médico representa o pai ou a mãe. Isto é verdade, mas o fenômeno de grupo, e sua dinâmica, não ficam suficientemente claros. Outra observação de Schilder é que as experiências humanas em seus niveis profundos são muito semelhantes. Assim, "culpa, ansiedade, dependência $€$ insegurança, permanecem como problemas individuais e podem ser levados a uma solução individual quando discutidos livremente no grupo". (A meu ver, o individuo se associa em grupo exatamente como meio de defesa contra ansiedade, culpa, etc., e, ao se analisar a estruturação do grupo como um todo, analisam-se, concomitantemente, estas ansiedades individuais). 
Slavson ${ }^{34}$ é, possìvelmente, o autor que mais tem escrito sôbre psicoterapia de grupo, inclusive a de orientação analítica. Sua contribuição aos outros métodos analíticos de grupo é escassa, se houver alguma.

Slavson introduz abundante terminologia para fatos perfeitamente conhecidos, e desde há muito, na psicanálise. Uma terminologia nova justifica-se plenamente quando se trata de uma disciplina nova, como é a psicoterapia de grupo. Mas Slavson não descreve nada de novo, limitando-se a encarar os pacientes em grupo como se estivessem em análise individual. Tanto a nova terminologia como as inúmeras classificações só compljcam a leitura de seus trábalhos.

Fuolkes ${ }^{15}$ afirma que a psicoterapia analítica de grupo é uma forma de psicoterapia e não uma forma de psicanálise. É uma aplicação dos conhecimentos psicanalíticos na análise do grupo e não na análise do psiquismo. Apesar desta afirmação, Foulkes não nos diz como se analisa o grupo. Cita, é verdade, elenıentos de grupo, como por exemplo a "reação de espelho" (mirror reaction) que. como agente terapêutico, consiste no fato do paciente se dar conta de que os outros têm "idéias mórbidas, angústias e impulsos semelhantes aos seus, o que diminui a angústia e culpa próprias, mesmo naqueles que só se limitam a escutar, sem uma participação direta". A "reação de espelho", tal como é enfocada, pode, a meu ver, diminuir ou acalmar a ansiedade, mas a solução da mesma depende de fenômenos mais profundos.

Ackerman ${ }^{1}$ acentua muito a importância da estruturação do grupo. Entretanto, não esclarece como isso se passa, nem indica como analisar essas estruturas. Afirma Ackerman que a redução da culpa e angústia se processa através da "universalização" das formas comuns de conflitos, fenômenos que correspondem à "reação de espelho" de Foulkes. Wolf 41 e Rosenbaum ${ }^{32}$ conduzem grupos com orientação semelhante à de Ackerman.

A denominada "Escola Psiquiátrica de Washington" reune atualmente o maior número de psiquiatras e psicólogos que se dedicam à investigação da psicoterapia de grupo "em grupo". Sob a supervisão de Florence Powdemaker e Jerome Frank, foram publicadas várias contribuições, entre as quais "Group Psychotherapy" ${ }_{26}$ que é a monografia mais extensa sôbre êste tema. A orientação por êles seguida, como afirmam, é a de Schilder, Slavson, Foulkes, Ackerman e Wolf.

\section{b) Orientação psicanalitica que visa o grupo}

Os trabalhos de Redl ${ }^{29}$ sempre levam em conta o grupo como um todo, correlacionando ainda o individuo ao grupo. Este autor ${ }^{2913}$ menciona cinco tipos de resistência de grupo, diferenciando-as das individuais. Afirma que em grupos uma resistência individual é difícil de ser mantida, mas pode permanecer encoberta por uma resistência de grupo.

No trabalho de Taylor e Rey ${ }^{3 i}$ sôbre a origem do fenômeno do "bode expiatório" pode observar-se como os autores se conduzem, dirigindo as interpretações a todos os componentes do grupo. Estes autores descrevem a 
indução (engieering) do fenômeno do "bode expiatório" em um grupo terapêutico, composto por mulheres, as quais induziram uma companheira a uma aventura sexual ilícita. Interpretada esta atuação devidamente $\in m$ função do grupo, tôdas se sentiram culpadas, porque tôdas "participaram" daquela ccorrência.

Bion ${ }^{4}$ é um dos autores que mais tem contribuído no sentido de salientar a importância do grupo como uma totalidade. Êle descreve as tensões que se desenvolvem no grupo e enfoca os problemas resuitantes em têrmos de "pressupostos básicos", de "dependência", "fuga-luta" e "acasalamento" ou "cópula".

A atividade mental do grupo acha-se dividida em duas partes. A primeira, cujas caracteristicas se assemelham ao Ego, Bicn denomina de "Group Work". Trata-se de uma atividade cuja cooperação é voluntária, decorrendo de anos de treinamento, experiência e desenvolvimento psíquico individual. $\dot{E}$ uma atividade relacionada à realidade e seus métodos são racionais. Mas esta atividade mental é frequientemente obstruida, desviada e ocasionalmente reforsada por outras que tem em comum os atributos de impulsos emocionais poderosos. Esta segunda atividade, aparentemente caótica, pode ser compreendida com mais coerência mediante a hipótese de que estas atividades mentais surgem de "pressupostos básicos" (basic assumptions) comuns a todos os grupos. Os três pressupostos básicos da atividade mental do grupo e seus respectivos líderes são os seguintes: (a) o pressuposto básico da dependência e seu respectivo lider, de quem depende a nutrição material e espiritual do grupo, bem como sua proteção; (b) o pressuposto básico da fuga-luta (flight-fight), que também tem o seu líder; (c) o pressuposto básico de que o grupo se reune para fins de "acasalamento" ou "cópula" (pairing), tudo se passando como se duas pessoas não pudessem se reunir a não ser para fins sexuais; seu líder, segundo Bion, pode ser mais bem descrito como o "gênio ainda não nascido", estando encoberto por "esperanças messiânicas". As participasōes nessas atividades não requerem experiência e independem de desenvolvimento mental. Elas são instantåneas, inevitáveis e instintivas, dependendo de que $o$ indivíduo possua o que Bion denomina de "valêncla", têrmo criado para expressar a capacidade de combinação voluntária e instantânea de um individuo com outro, para participar e agir em função do pressuposto básico.

É possivel que se os pressupostos básicos inconscientes de Bion fôssem descritos em têrmos de tendências ou fases - orais, sádico-anais e genitais - das relações de objeto correspondentes às mesmas, êles se tornassem mais claros e mais familiares.

Mas isto não impede que possam ser encontradas, nas contribuições de Bion, indicações extremamente úteis para compressão e interpretação do grupo em formas acessíveis, como por exemplo, a sua indicação de que a vida emocional do grupo só pode ser entendida em têrmos de mecanismos psicóticos. Não obstante a aceitação dos métodos de Bion por grande número de autores, verifica-se que êstes não utilizam seus conceitos, o que talvez se deva não só à terminologia como, principalmente, ao exclusivismo de seus pontos de vista.

As contribuições de Ezriel ${ }^{13}$, derivadas dos trabalhos de Bion, acentuam a importância da transferência. As interpretações em grupo baseiam-se no fato de que as ações e pensamentos, aparentemente incoerentes, expressos em grupos, pelos diversos componentes. em seqüência temporal, estão rela- 
cionados dinâmicamente. Isto significa que existe uma fonte dinâmica inconsciente comum, uma necessidade, que atinge determinada tensão na mente dos pacientes e que procura alivio através do estabelecimento de certa relação entre êles e o analista, na situação do "aqui" e "agora" da sessão analitica.

O conteúdo manifesto das discussões pode versar sôbre qualquer tópico, mas sempre se desenvolve ràpidamente e se encontra subjacente (ao conteúdo manifesto) "um problema comum aos componentes, uma tensão comum da qual o grupo não tem consciência mais que determina sua conduta". A essa tensão comum do grupo, Ezriel designa de "denominador comum das fantasias inconscientes dominantes de todos seus membros".

Segundo Ezriel, as interpretaçoes efetivas são as transferenciais, dirigidas primàriamente ao denominador comum. As interpretações individuais são desaconselhadas, a não ser quando é possivel demonstrar ao paciente: (a) que sua conduta representa seu modo específico de cobrir a tensão comum; (b) os motivos porque êle age preferentemente desta forma em vez de outras.

Sutherland ${ }^{36}$ afirma que sua orientação está baseada nas três hipóteses utilizadas por Ezriel: a primeira é a teoria psicanalítica das relaçōes inconscientes de objeto e da transferência; a segunda é a da "tensão comum do grupo"; a terceira refere-se àquilo que é capaz de produzir modificações na personalidade dos membros do grupo (experiência da realidade do grupo e interpretação das respostas individuais à tensão comum do grupo). Segundo Sutherland, a natureza essencial do processo terapêutico da psicoterapia de grupo é a mesma da análise individual.

Lebovici ${ }^{20}$ e Dreyfus-Moreau ${ }^{12}$ seguem, em linhas gerais, a mesma orientação de Ezriel.

Bahia ${ }^{3}$ conduz grupos com normas estritamente psicanaliticas, com a mesma atitude da análise individual: é sempre neutro, abstencionista e responde ùnicamente com a interpretação. Segundo se depreende de seu trabalho, Bahia difere dos autores mencionados por interpretar inicialmente aos componentes do grupo e, no fim, a êste como um todo.

\section{COMENTARIOS}

A grande maioria dos autores, de quaisquer dos métodos citados, menciona resultados favoráveis: pelo menos modificaçōes ou desaparecimento dos sintomas. Não há afirmações concludentes, mesmo no método analítico de grupo, de modificações profundas e duradouras na personalidade dos pacientes, não tendo sido resolvida ainda a questão da possibilidade efetiva de elaboração de conflitos e da medida em que isto pode ocorrer.

Dito isto, será útil uma revisão dos diversos métodos de psicoterapia de grupo enfocados, visando compreender como funcionam os grupos e o modo pelo qual atua o tratamento.

No método repressivo verifica-se como não são levados em conta os conflitos inconscientes, o que significa que não são tocadas as verdadeiras origens dos sintomas neuróticos; trata-se, simplesmente, de reprimi-los ou ne- 
gá-los. O poder mágico das palavras reina absoluto neste método. Espera-se que, com a substituição dos pensamentos conscientes, operada através de novas expressōes verbais, o estado dos pacientes se modifique fundamentalmente. A relação entre o psicoterapeuta e o grupo é de franca submissão dêste à autoridade daquele.

No método didático, a repressão é dominante, se bem que o procedimento não seja tão ostensivo. A repressão fica disfarçada sob um manto de compreensão intelectual. A técnica usada é mais sedutora e menos direta que no método precedente, atuando a repressão a partir dos conhecimentos intelectuais proporcionados aos pacientes acêrca de seus sintomas e ansiedades. A relação que se estabelece entre o psicoterapeuta e o grupo é de submissão a um pai ou mãe que nutre intelectualmente o Ego dos pacientes.

O psicodrama é uma psicoterapia de grupo difícil de ser compreendida em sua totalidade nos têrmos em que atualmente se encontra conceituada, especialmente se apreciada sob as complexas concepções de Moreno. Mas, deixando de lado estas concepções, encontram-se elementos de valor no trabalho de Moreno a serem revisados à luz da experiência psicanalítica.

No método psicanalítico, o meio pelo qual se tenta obter as modificações desejadas, como na análise individual, são as interpretações transferenciais. Em relação a êste dado fundamental, devem ser consideradas as duas orientações existentes na psicoterapia analítica de grupo: aquela que analisa primordialmente o individuo no grupo e a que focaliza o grupo como uma totalidade. $\mathrm{Na}$ primeira, as interpretações dirigidas aos componentes, individualmente, não levam em conta a estruturação do grupo como uma entidade dinâmica, não aproveitando, portanto, as novas possibilidades que resultam da situação do tratamento realizado em grupo. Entre outros inconvenientes dêste procedimento pode ser mencionado o precoce abandono do tratamento pelos pacientes, a agravação dos sintomas e a ocorrência de situaçōes do tipo caótico. Isto se deve ao fato das interpretações individuais poderem ser fàcilmente vividas pelos pacientes como criticas por uns e sensação de abandono por outros. Ademais, a falta de interpretações ao grupo opõe-se à sua tendência natural a uma integração unitária. Contratransferencialmente, a atitude de interpretação individual deve corresponder a uma defesa do terapeuta em face de ansiedades despertadas pela ação envolvente do grupo, ansiedades que o médico prosura evitar, como fazem também os pacientes, agindo de acôrdo com a fórmula "dividir para reinar".

\section{RESUMO}

Nesta revisão é salientado o desenvolvimento e a importância atual da psicoterapia de grupo. O autor, baseado em sua experiência em psicoterapia analítica de grupo, faz um estudo critico dos principais métodos empregados, passando em revista as contribuições mais representativas dos métodos repressivo, didático, psicodramático e psicanalítico. Divide êste último em 
duas orientações fundamentais: uma em que as interpretações do psicoterapeuta visam os pacientes do grupo e a outra que focaliza primordialmente o grupo como um todo, como uma unidade dinâmica.

A grande maioria dos autores menciona resultados terapêticos favoráveis, pelo menos modificações ou desaparecimento de sintomas, mas não há ainda afirmaçōes concludentes de modificaçōes profundas e duradouras na personalidade dos pacientes. Quanto ao modo como atua o tratamento, nos métodos repressivo e didático, verifica-se fàcilmente como não são levados em conta os conflitos inconscientes, o que significa que não são tocadas as verdadeiras origens dos sintomas neuróticos. A ação terapèutica do método psicodramático, pelo menos nos têrmos em que se encontra atualmente conceituada, é difícil de ser apreciada devidamente, merecendo, entretanto, uma revisão à luz da experiência psicanalítica.

No método psicanalítico, o instrumento técnico pelo qual se tenta obter as modificações desejadas, como na análise individual, são as interpretaçōes transferenciais. Cita-se os inconvenientes da orientação em que as inter. pretações focalizam predominantemente os pacientes no grupo e conclui-se ser a orientação que visa o grupo como um todo a única que se apresenta adequada ao manejo técnico das situações clínicas e oferece mais possibilidades terapêuticas afetivas. Sugere-se ainda o motivo do terapeuta interpretar aos individuos do grupo: trata-se de uma defesa contra-transferencial contra as ansiedades despertadas pela ação envolvente do grupo.

\section{SUMMARY}

\section{The different approaches to group psychoterapy}

A review is presented concerning the importance and the progress of group psychotherapy. On the basis of his personal experience with analytical group prychotherapy, the author makes an appraisal of the most important methods which have been used, reviewing the most representative contributions of the repressive, didactic, psychodramatic and psychoanalytic methods. The psychoanalytic method is considered along two different orientations: a) in which the psychotherapist's interpretations are aimed at the individuals of the group; b) in which the interpretations are directed to the group as a whole, that is, as a dynamic unit.

The majority of the authors reviewed register favourable therapeutic results, reporting at least changes or disappearance of symptoms. However there has not been any conclusive study reporting deep and lasting personality changes. As to the mode of action of the different methods, the following can be said: in the repressive and didactic methods one can readily see that inconscient conflicts are not taken into consideration, which means that these methods do not touch the true origins of neurotic symptoms; the therapeutic action of the psychodrama as it is now conceived, is difficult to appreciate, deserving further studies through an appraisal from the point of view of psychoanalytical experience. 
In the psychoanalytic method of group therapy the technical instrument through which one attempts to obtain the desired changes is the transferencial interpretations, as it is in individual analysis. However, the author stress the difference between the two mentioned orientations describing the inconveniences of the one in which the interpretations are aimed predominantly at the individuals in the group. The author concludes that the other orientation, in which the interpretations are directed to the group as a whole, is the only one that is adequate to the management of clinical situations and offers more effective therapeutic possibilities. The author also suggest that the psychotherapist's motives for giving interpretations to the individuals in the group is an attitude of defense (counter-transference) against anxiety arisen in him by involving action of the group.

\section{REFERENCIAS BIBLIOGRAFICAS}

1. ACKERMAN, N. W. - a) Group therapy from viewpoint of a psychiatrist. Am. J. Orthospsychiat., 31:667, 1943; b) Dynamic patterns in group psychotherapy. Psychiatry, 7:341, 1944; c) Some theoretical aspects of group psychotherapy. In Group Psychotherapy. J. L. Moreno ed., Beacon House, New York, 1945; d) Interterview group psychotherapy with psychoneurotic adults. In The Practice of Group Therapy, S. R. Slavson ed., International Universities Press, New YorK, 1947; e) Some structural problems in the relations of psychoanalysis and group psychotherapy. Int. J. Group Psychoter., 4:131, 1954; f) Interaction processes in a group and the role of the leader. International Universities Press, New York, 1955. 2. ALTSHULER, I. M. - The organism-as-a-whole and music therapy. In Group Psychotherapy, J. L. Moreno ed. Beacon House, New York, 1945. 3. BAHIA, A. B. - Experiências psicanaliticas em terapia de grupo. Medicina, Cirurgia e Farmácia (Rio de Janeiro), 220:333, 1954. 4. BION, W. R. - a) Experiences in groups I. Hum. Relat., 1:314, 1948; b) Experiences in groups II. Hum. Relat., 1:487, 1948; c) Experiences in groups III. Hum. Relat., 2:13, 1949; d) Experiences in groups IV. Hum. Relat., 2: $295,1949 ; e)$ Experiences in groups V. Hum. Relat., 3:5, 1950; $f$ ) Experiences in groups VI. Hum. Relat., 3:395, 1950; $g$ ) Experiences in groups VIr. Hum. Relat., 4:421, 1951; $h$ ) Group dynamics: a review. Int. J. Psycho-Anal., 33:235, 1952.5. BION, W. R.; RICKMAN, J. - Intra-group tensions in therapy. Lancet, 2:678, 1943. 6. BLACKMANN, N. - Experiences with a literary club in the group treatment of schizophrenia. J. Occupational Therapy, 19:293, 1940. 7. BUCK, R. W. - Class method in treatment of essential hypertension. Am. Int. Med., 11:511, 1937. 8. CHACE, M. - Thythm in movement as used in St. Elizabeths Hospital. In Group Psychotherapy, J. L. Moreno ed., Beacon House, New York, 1945. 9. CHAPPEL, M. N.; STAFANO, J. J.; ROGERSON, J. S.; PIKE, F. H. - Value of group psychological procedures in treatment of peptic ulcer. Amer. J. Digest. Dis. \& Nut., 3:813, 1937. 10. COHEN, R. R. - Visual aids in group psychotherapy. In Group Psychotherapy, J. L. Moreno ed., Beacon House, New York, 1945. 11. DREIKURS, R.; CORSINI, R. - Twenty years of group psychotherapy: purposes, methods and mechanisms. Am. J. Psychiatry, 110:567, 1954. 12. DREYFUS-MOREAU, J. — Bilan d'une expérience colletive.e Rev. Francaise de Psychanalyse, 19:333, 1955. 13. EZRIEL, H. - a) A psychoanalytic approach to group treatment. Brit. J. Med. Psychol., 23:59, 1950; b) Notes on Psychoanalytic Group Therapy: interpretation and research. Psychiatry, 15: 119, 1952. 14. FANTEL, E. - Psychodrama in an evacuation hospital. In Group Psychoterapy, J. L. Moreno ed., Beacon House, New York, 1945. 15, FOULKES, S. H. - a) On group analysis. Int. J. Psychoanal., 27:46, 1946; b) Introduction to GroupAnalytic Psychotherapy, William Heinemann Medical Books Ltd., London, 1948; $c$ ) Some similarities and differences between psychoanalytic principles and group-analytic principles. Brit. J. Med. Psychol., 26:30, 1953; d) Group-analytic observation. Inter. 
J. Psycho. Anal., 35:263, 1954. 16. HARRIS, H. I. - Efficient psychotherapy for the large outpatients clinic. New England J. Med., 221:1, 1939 . 17. HERRIOT, F. - Some use of psychodrama at St. Elizabeths Hospital. In Group Psychotherapy, J. L. Moreno ed., Beacon House, New York, 1945. 18. KLAPMANN, J. W. - Group Psychotherapy: Theory and Practice Grune \& Stratton, New York, 1947. 19. LAZELL, E. W. - $a$ ) The group treatment of dementia praecox. Psychoanalyst. Tev., 8:168, 1921; b) Group psychotherapy. In Group Psychotinerapy, J. L. Moreno ed., Beacon House, New York, 1945. 20. LEBOVICI, S. — A propos de la psychanalyse de group. Rev. Française de Psychanalyse, 17:226, 1953. 21. LOW, A. A. - The combined system of group psychotherapy and self-help. In Group Psychotherapy, J. L. Moreno ed., Beacon House, New York, 1945. 22. MARSH, L. C. - a) Experiment in group treatment of patients at Worcester State Hospital. Ment. Hyg., 17:396, 1933; b) Group therapy and the psychiatric clinic. J. Nerv. a. Mental Dis., 82:381, 1935. 23. MC KAY, L. A. - Music in the treatment of convalescents. In Group Psychotherapy, J. L. Moreno ed., Beacon House, New York, 1945. 24. MÚLLER, A. Le psychodrame selon Moreno. Rev. Française de Psychoanalyse, 16:416, 1952.25. NOYES, A. P. - a) Modern Clinical Psychiatry, Third Edition. W. B. Saunders Co. Philadelphia \& London, 1948; b) Modern Clinical Psychiatry, Fourth Edition. W. B. Saunders Co.. Philadelphia \& London, 1953. 26. POWDERMAKER, F.; FRANK, J. Group Psychotherapy. Studies in Methodology of Research and Therapy. Harvard University Press, Mass., 1953. 27. PRADOS, M. - Special technical aspects of group psychotherapy. Int. J. Group Psychoter., 2:131, 1953. 28. PRATT, J. H. - a) The home sanatorium treatment of consumption. Johns Hopkins Hosp. Bull., 17:140, 1906; b) The group method in the treatment of psychosomatic disorders. In Group Psychotherapy, J. L. Moreno ed., Beacon House, New York, 1945. 29. REDL, F. - a) Group emotion and leadership. Psychiatry, 5:575, 1942; b) Resistence in Therapy Groups. Hum. Relat., 1:307, 1948. 30. RHOADES, W. - Group training in thought control for relieving nervous disorders. Ment. Hyg., 19:373, 1935. 31. ROME, H. P. - Therapeutic films and group psychotherapy. In Group Psychotherapy, J. L. Moreno ed., Beacon House, New York, 1945. 32. ROSENBAUM, M. - The challange of group psychoanalysis. Psychoanalysis, 1:42, 1952. 33. SCHILDER, P. - $-a$ ) Results and problems of group psychotherapy in severe neuroses. Mental Hyg., 23:87, 1939; $b$ ) Introdutory remarks on groups. J. Social Psychol., 12:83, 1940. 34. SLAVSON, S. R. - a) General Principles and Dynaamics in the Practice of Group-therapy. International Universities Press, New York, 1947; b) Analytic Group Psychotherapy. Columbia Universities Press, New York, 1951; c) Common sources of error and confusion in group psychotherapy. Int. J. Group Psychother., 2:3, 1953; $d$ ) Contribution to a systematic theory of group psychotherapy. Int. J. Group Psychother., 4: $253,1954 ; e)$ Syndrome versus symptom in group psychotherapy. In The Fields of Group Psychotherapy. International Universities Press, New York, 1956. 35. SNOWDEN, E. N. - Mass psychotherapy. Lancet, 2:769, 1940. 36. SUTHERLAND, J. D. Notes on psychoanalytic group therapy: interpretation and research. Psychiatrâ, 15: 119, 1952. 37. TAYLOR, F. K.; REY, J. H. - The scapegoat motif in society and its manifestations in a therapeutic group. Int. J. Psychoanal., 34:253, $1953,38$. THOMAS, G. W. - Group psychotherapy. A review of the recent literature. Psychosomatic Med., 5:166, 1943. 39. WARD, M. H. - Note on psychomusic and musical group psychotherapy. In Group Psychotherapy, J. L. Moreno ed., Beacon House, New York, 1945. 40. WENDER, L. - a) The dynamics of group psychotherapy and its application. J. Nerv. a. Ment. Dis., 84:54, 1936; b) Group Psychotherapy. In Group Psychotherapy, J. L. Moreno ed., Beacon House, New York, 1945. 41. WOLF, A. $\rightarrow$ Sexual acting out in the psychoanalysis of groups. Int. J. Groups Psychother., 4: $469,1954$.

Avenida Senador Salgado Filho, 204, aparto 21 - Pôrto Alegre, Rio Grande do Sul, Brasil. 